\title{
Fragmentação e heterogeneidade na cultura latino-americana dos anos 20
}

Viviana Gelado

lo que menos se improvisa es la cultura

José Vasconcelos, Memorias, t.II, p.16

O objetivo deste trabalho é o de mostrar algumas perspectivas polêmicas gerais formuladas no período de surgimento e auge dos movimentos de vanguarda na América Latina, através da problematização de um aspecto pouco tratado pela crítica especializada: a função estético-ideológica que fragmentação e heterogeneidade desempenham na produção vanguardista latino-americana e, em especial, em relação ao tratamento dado por ela a diversas matrizes da cultura popular, tomadas como matéria de incitação estética dentro de uma estratégia de valorização das mesmas e como meio de questionamento da "arte como instituição". Com esse intuito, discutiremos as referências ao assunto presentes na bibliografia teórica sobre a vanguarda e adotaremos, no que diz respeito aos conceitos de cultura e cultura popular, a perspectiva traçada pelo culturalismo inglês e por estudos de antropologia cultural e crítica literária no âmbito latino-americano.

Para começar, se observamos a noção de valor do ponto de vista da sociologia literária como sujeita a variáveis ideológico-estéticas e históricas, é possível perceber em diversos manifestos, programas e outras obras produzidos pelos movimentos de vanguarda na América Latina uma operação deliberada de valorização do popular. Esta operação, como veremos, se dá tanto no sentido de procurar a incorporação do popular ao sistema (uma operação que daria continuidade a um relativismo estético, pelo qual a noção de valor estabeleceria um dentro/fora do sistema e os movimentos de vanguarda funcionariam como introdutores ou tradutores do popular para esse sistema, contra o qual, paradoxalmente, eles teriam se insurgido); quanto, mais radicalmente, com o intuito de promover a ruptura da dicotomia entre arte "alta" e "cultura popular" (e, conseqüentemente, expondo o caráter variável, histórica e socialmente, da noção de valor estético). $\mathrm{Na}$ medida em que, no consumo de bens simbólicos, o valor não é percebido como relativo, a segunda postura, mais radical, é melhor condizente tanto com o problema que coloca o valor enquanto categoria estética, quanto com o próprio fenômeno da vanguarda.

Por outra parte, a promoção da ruptura da dicotomia entre arte ou cultura "alta" e "cultura popular" pelos movimentos de vanguarda, tanto na Europa como na América Latina, se sustenta na aposta maciça feita por eles na noção de cultura por oposição à de civilização ${ }^{1}$, adotada esta última como bandeira, no continente, pelos intelectuais dos movimentos da década anterior, contemporâneos aos centenários das independências nacionais. Esta mudança implica historicamente em uma consideração mais matizada em relação ao projeto de modernização exaltado pelas gerações precedentes, desde o positivismo 
imperante na década de oitenta do século XIX, e seu otimismo endêmico. A ênfase na cultura, contra a civilização, aposta em uma modernização mais eqüitativa, deixando à vista as mazelas que a imposição do modelo adotado pelas oligarquias locais já evidenciava na época. Esta escolha feita pelos movimentos de vanguarda diz respeito, sobretudo, à adoção de uma visão menos apriorística e, portanto, mais complexa e em profundidade do âmbito social e, particularmente, dos bens simbólicos produzidos e consumidos pelos diversos grupos que o integram.

Enunciados conseqüentes com esta postura, as referências à "alta" cultura e seus sucedâneos ([a] "peste dos chamados povos cultos e cristianizados" ) se multiplicam nos manifestos de vanguarda sempre carregadas de mofa e sarcasmo. E mais radicalmente, a civilização ocidental, cuja decadência tinha sido anunciada por Spengler, e sobretudo sua feição contemporânea, a da civilização técnica, se transformarão no "bárbaro tecnizado", mais representativo da volta ao "instinto caraíba" apregoada pelo Manifesto antropófago de Oswald de Andrade. É contra a concepção utilitarista e iluminista da cultura como "modo de vida superior", em termos de Raymond Williams, que a vanguarda se insurge.

Já Leenhardt apontara como condição de surgimento dos movimentos de vanguarda na Europa, particularmente na Alemanha, este confronto entre a "verdadeira cultura" e a "civilização técnica, burocrática, racionalista e burguesa", por imposição desta última. Deste confronto resulta, na virada do século, um sentimento de desencantamento como diagnóstico social, que acaba sendo oportunamente aproveitado e acha paradoxalmente vazão no novo âmbito da cultura, compreendida como projeto político estatal moldado pela burguesia, e cuja primeira representação institucional importante estará constituída pela escola. A começos do século XX, segundo este autor, já é claro, para escritores e artistas, que a cultura faz parte da estratégia política do poder. ${ }^{3}$

Embora participando no processo de modernização de maneira fragmentada, há evidências do apontado por Leenhardt também na América Latina, tanto no que diz respeito ao teor do confronto quanto ao modelo de modernização a que responde e ao momento de sua implementação. Com efeito, e apesar de ter se iniciado, no período que nos ocupa e por iniciativa dos movimentos de vanguarda, o debate intelectual em torno das categorias de cultura e civilização, o mesmo se alastrará durante a década de vinte e se acirrará na de trinta, quando o Estado pretenda monopolizar a cena pública mediante práticas populistas, inclusive no campo intelectual. O próprio teor do papel atribuído à instituição escolar, à revelia do desejado muitas vezes pelos intelectuais que fizeram parte dos movimentos de vanguarda na região, é representativo do projeto traçado pelas oligarquias locais, interessadas em promover uma integração forçada dos setores subalternos a um projeto nacional de desenvolvimento que as perpetuasse como setor hegemônico; no caso do México, por exemplo, o programa de alfabetização implementado por Vasconcelos após a Revolução revestirá elementos bastante contraditórios.

Neste sentido poderíamos levantar duas questões. Uma é a da instituição da cultura por parte das oligarquias, apoiadas pelo Estado, distinta e até antagônica em relação à idéia de cultura dos setores sociais subalternos, cujas demandas o populismo demagógico estatal precisa em parte atender. Com efeito, a oligarquia e o Estado continuarão entendendo por cultura, a escrita, ocidental e urbana; enquanto que os setores sociais subalternos a 
compreenderão como um todo do qual participam também diversas práticas orais (religiosas, estéticas, políticas) plasmadas em diversos códigos (pictórico, gestual, musical). Assim, ao propor a ruptura dos gêneros e o ataque à arte e à cultura como instituições, através do diálogo entre diversos códigos, gêneros e registros de linguagem, os movimentos de vanguarda transformam o âmbito da cultura e o próprio "texto" literário (manifestos, prefácios, narrativa, poema) em campo de batalha. ${ }^{4}$ Outra questão é a de que essa disputa pelo poder, travada no âmbito da cultura entre os intelectuais e o Estado, não constituiu uma absoluta novidade no período, posto que estes exerceram habitualmente funções públicas no continente desde os movimentos de independência no século anterior; a novidade estará sim no fato de que sua crescente profissionalização os irá afastando do exercício do poder público. Este fenômeno é especialmente claro como expressão do processo de legitimação dos setores intelectuais das classes médias, que disputam com a oligarquia uma representatividade "nacional", e portanto política, que englobe também os setores subalternos, os quais os intelectuais dos setores médios dizem também representar, no âmbito da cultura.

No que se refere à implementação pelo Estado do conjunto de medidas que fazem parte do processo de modernização, o modelo a que respondem, importado, foi sendo implantado de maneira bastante irregular na região. ${ }^{5}$ No entanto, os projetos sociais relativos a âmbitos tais como o da educação e a cultura foram postos em prática de maneira relativamente rápida e, em alguns casos, tentativamente homogênea. A modo de exemplo, as primeiras campanhas de alfabetização em massa são contemporâneas na Alemanha e na Argentina: ambas se iniciaram na década de oitenta do século XIX.

É interessante destacar ainda que, se bem a mencionada disputa pelo poder no âmbito da cultura entre intelectuais e Estado é nova, a relação de homologação entre o popular e o nacional é de matriz romântica. Com efeito, na introdução à publicação de trabalhos apresentados ao primeiro Congresso Internacional das Artes Populares, realizado em Praga em 1928, Henri Focillon chama a atenção para o solapamento dos aspectos ideológicos existentes por trás destas categorias e para sua inoperância em termos técnicos e formais, além de apontar os problemas que a indústria cultural já colocava na época para as culturas populares ou periféricas. Em um texto breve, instigante e extremamente esclarecedor do ponto de vista teórico, embora ligado um pouco ao classicismo em sua perspectiva, Focillon se concentra no delineamento de constantes formais nas artes populares, em oposição às supostas determinações nacionais ou raciais que agiriam sobre as mesmas. Assim, analisa as diferenças entre "a idéia de uma arte desinteressada, superior e livre, criada para o prazer de pequenos universos inúteis" e "a idéia de uma arte ligada à função, ao objeto, às comodidades da existência, uma arte que serve, como a lei moral, como a técnica religiosa", à luz de três categorias: tempo, espaço e ação.

No que diz respeito à primeira delas, Focillon distingue com argúcia entre "o espírito de novidade" e "a invenção" enquanto "função das ondas curtas", por um lado, e "as sobrevivências" das "culturas do tempo em câmara lenta", pelo outro. Já no que se refere às outras duas categorias, a distinção é traçada entre uma arte que vê antes de conceber (e que procede pelo acúmulo dos "resultados de [sucessivas] descobertas"), por um lado, e a arte que concebe antes de ver, e na qual o espaço aparece como indeterminado e as formas conceituais se encadeiam, uma arte que exibe um "poderoso instinto da ordem" e um 
"sentido harmônico da cor", por outro. Estes últimos espaço e ação seriam os das artes "das crianças, dos primitivos" e também os "das artes populares". 6

De grande importância para o objetivo aqui proposto, a distinção traçada por Focillon no que se refere ao tempo e à ação, nos ajudará a mostrar, em geral, a complexidade e paradoxos da modernidade latino-americana e, em particular, os perceptíveis no terreno das artes plásticas mexicanas no período das vanguardas. Com efeito, é possível ver que tanto os manifestos quanto a execução de alguns murais e gravuras devem sua originalidade não somente à invenção mas sobretudo à combinação de técnicas utilizadas pelas artes indígena, popular e moderna, e que não apenas constituem uma apropriação moderna superficial ou pitoresquista de uma temática indígena ou popular datadas historicamente.

Contemporaneamente à introdução de Focillon e preocupado também pela assimilação do popular ao nacional, embora desde uma perspectiva mais ligada ao econômico e social e à luta de classes, Gramsci se esforçará em resgatar a cultura do povo italiano no seu estatuto de cultura em contradição com as determinações do Estado fascista, postulando-a como lugar de reserva moral na disputa pela hegemonia travada entre o povo e o Estado. O que nos interessa particularmente nesta postulação é sua concepção da cultura, para além do estritamente "artístico", como "modo de conceber o mundo e a vida, em contraste com a sociedade oficial" e a diversidade de produções e relações entre a intelectualidade e o povo por ele consideradas como populares: tanto pela universalidade da representação; quanto pela possibilidade de transformar em crítica social a representação de situações produzidas pelo povo; quanto, ainda, pela representação dos "sentimentos populares" em diversos moldes (incluídos neles o melodrama e o folhetim). ${ }^{7}$ Neste sentido, é possível constatarmos, no âmbito da cultura latino-americana e no período que nos ocupa, a presença destas representações tanto em obras individuais quanto em empreendimentos coletivos e institucionais, como adiante veremos.

A postulação da inevitabilidade da disputa pelo poder no âmbito da cultura entre intelectuais e povo, por um lado, e o Estado, por outro, acarreta como conseqüência o aumento da dificuldade em separar o popular do nacional. Assim, e embora não constitua o principal objeto de análise deste trabalho, apontaremos também adiante em que medida algumas das produções da vanguarda latino-americana são representativas desta dificuldade.

Em geral, é possível perceber uma preocupação estética em relação ao popular em diferentes âmbitos das artes neste período em todo o continente. Assim, na música, o percurso realizado por Heitor Villa-Lobos em sua formação, do estudo de gêneros e motivos populares à temática nacionalista ${ }^{8}$; a recuperação, por Carlos Chávez e Silvestre Revueltas, de "la música ritual de los indios mexicanos" e dos elementos fundamentais da arte popular mexicana, adaptados a uma expressão artística moderna; os temas e estruturas rítmicas folclóricos argentinos que inspiraram a produção musical de Alberto Ginastera um pouco mais tarde, nas décadas de 30 e 40, e que aparecem sintetizados com elementos politonares e dodecafônicos ${ }^{10}$.

E na pintura, os motivos, técnicas e personagens da tradição indígena e da popular recuperados pelo muralismo mexicano e pelos gravuristas contemporâneos a este movimento; a incorporação dos dizeres da crônica diária à maneira do corrido e da literatura de 
cordel nos murais de Rivera e na pintura de cavalete de Frida Kahlo (-Unos cuantos piquetitos!, 1935); as personagens e temas escolhidos por Portocarrero, Portinari, Di Cavalcanti e, em ocasiões, também por Pettoruti (La canción del pueblo de 1927) e Xul Solar (as Cuatro cholas de 1923); as cores "caipiras" da pintura de Tarsila do Amaral entre 1923 e 1927; e os motivos, danças e cenas populares que inspiraram, entre outros, os Candombe de Pedro Figari em 1921 são também representativos desta preocupação. Ainda no âmbito pictórico, entre os artistas citados é possível distinguir aqueles em cuja obra, em termos gerais na década de vinte, o popular aparece mais associado ao âmbito rural - assim nas personagens ou temas de Portocarrero, Portinari e Tarsila do Amaral - e aqueles cujas personagens e temas populares retratados pertencem maioritariamente ao âmbito urbano ou suburbano - os rio-platenses Figari e Pettoruti.

No literário, uma análise contrastiva de diversos textos programáticos e polêmicos e de outras produções individuais ou grupais revela zonas de conflito no que tange à relação com o popular. A partir da análise dos mesmos seria possível estabelecer os eixos de tensão surgidos entre os diversos grupos de vanguarda em relação às estratégias de tratamento estético do popular, representados, muitas vezes, através do caráter performático da polêmica. Seria possível também observar quais dos elementos programáticos relativos a - em prol e em contra - formas artísticas populares foram paradoxal e significativamente esquecidos nas produções individuais. Veremos aqui, pois, um panorama das formas que revestiu programaticamente a valorização do popular entre os diversos grupos de vanguarda na América Latina.

Na história da literatura latino-americana, a popular foi talvez a série mais questionada inicialmente pela produção modernista hispano-americana e pelo Parnasianismo brasileiro, excetuando a recuperação do romanceiro tradicional hispânico na obra de Leopoldo Lugones e, um pouco antes e depois deste período, o sencillismo de Martí e o prosaísmo de Fernández Moreno ou López Velarde. ${ }^{11}$ Os movimentos de vanguarda posteriores seguiram o Modernismo hispano-americano em alguns tópicos (como o exotismo oriental, presente ainda nos primeiros livros de Tablada e Huidobro) e inovações formais (como a espacialização do discurso poético). No entanto, no período vanguardista - período no qual se radicalizou a experimentação formal - o tratamento do popular, tanto desde o ponto de vista temático quanto desde o ponto de vista estritamente formal, não foi rejeitado de maneira homogênea. Ao contrário, a diversidade de realizações que atualizaram seu tratamento revela, por um lado, o caráter complexo e rico do popular e conseqüentemente, por outro, a problemática estética peculiar que impõe seu tratamento neste período.

Assim, pois, em relação ao caráter da cultura popular, García Canclini afirmará que esta "es el resultado de la apropiación desigual de los bienes económicos y culturales por parte de los sectores subalternos" (indígenas, camponeses, operários, urbanos, de massa). Com efeito e dados os termos em que se formula o debate sobre tradição, modernidade e pós-modernidade na América Latina; convindo entender por moderno "el desarrollo social basado en la industrialización, la urbanización intensiva y la reorganización masiva de las comunicaciones"; e considerando que cada um destes fenômenos da modernidade define âmbitos distintivos: o operário, o urbano e o das comunicações de massa, García Canclini estenderá o domínio dos estudos antropológicos sobre cultura popular e englobará nela as manifestações de diversos setores sociais cujo denominador comum é a subalternidade. ${ }^{12}$ 
De fato, se se levam em conta as peculiaridades e paradoxos da modernidade na América Latina ${ }^{13}$, particularmente no que se refere à falta de homogeneidade e à implementação - em geral, tardiamente - da industrialização e da reorganização em massa das comunicações, se faz necessária a adoção de definições mais laxas que possibilitem a análise das diversas manifestações culturais concomitantes ou conseqüentes a estes processos em sua espessura e contradições. Desde nossa perspectiva, e para uma compreensão mais cabal da produção estética do período que nos ocupa, a definição de cultura como "todo um modo de vida, material, intelectual e espiritual", adotada por Raymond Williams e retomada por García Canclini, se revela como mais operativa. Esta definição, de inspiração antropológica, questiona o valor atribuído a ela pela cultura burguesa (cultura como sinônimo de produções "doutas", intelectuais e morais) e o individualismo inerente ao mercado capitalista, reivindicando espaços de análise que transcendem o estritamente literário ou artístico; e inclui modos de vida e, especialmente, criações institucionais (associações, sindicatos, mutuais, cooperativas) mais características dos setores populares ou operários, através das quais se articula a produção e recepção de bens simbólicos. ${ }^{14}$

A este respeito diz também Beatriz Sarlo,

reconocemos a la cultura como un conjunto de sistemas de comunicación, ordenamiento, conocimiento, experimentación, creación: precisamente, un conjunto de sistemas, y no un magma en el cual son ilegítimas las contraposiciones y las escisiones. Que la cultura pueda ser vivida como un continuum, no supone necesariamente que deba ser descripta como tal.

E especificamente,

el estudio de las culturas populares (o, en el caso urbano moderno, mejor sería decir la dimensión cultural popular) está tan ligado a valores como cualquiera de los que se desarrollan en el campo de las ciencias sociales. No se trata de extirparlos sino de volverlos explícitos. Decir, como dijo Gramsci, que las culturas populares son por definición más fragmentarias [...] no supone condenar a las culturas populares a un infierno, sino registrar las marcas que en sociedades económica y políticamente desiguales ha dejado el proceso de constitución de las elites y de los sectores populares. ${ }^{15}$

Com efeito, esta fragmentação está potencializada no plano dos discursos, neste período, pelas inovações técnicas advindas, por exemplo, do campo tipográfico e, em geral, dos meios de produção e de reprodução e consumo de bens simbólicos através dos meios de comunicação disponíveis na recente e parcial modernização latino-americana. Em outras palavras, nas práticas de produção e consumo de bens simbólicos, aos suplementos literários dos grandes jornais, os semanários ilustrados e as revistas especializadas se somarão, na década de vinte, um sem-fim de revistas culturais de diverso teor e formato (que veicularão mais acentuadamente, em alguns casos, uma noção de cultura como "modo de vida"); séries e coleções de textos literários e científicos em folhetos ou encadernação rústica, distribuídas não através do circuito exclusivo das livrarias mas do circuito aberto e em expansão da imprensa periódica; o rádio, que inicialmente entenderá a cultura à maneira dos suplementos literários tradicionais e prolongará seu labor "formador do gosto" dos 
setores médios e populares com emissões de óperas, mas que, progressivamente, irá abrindo espaço em sua programação para diversas manifestações da cultura popular; o cinema documentário e de ficção; a indústria fonográfica, que difundia tanto árias de ópera, quanto "valores locais" da música popular e jaž bands. O conjunto destes meios de produção e reprodução de bens simbólicos traçará um mapa cultural mais complexo que o tradicional, que tinha dividido o campo cultural em manifestações de "alta" e "baixa” cultura. Graças principalmente aos projetos editoriais de barateio do livro, ao rádio e ao cinema, os setores urbanos e rurais medianamente alfabetizados poderão aceder ao consumo de bens simbólicos que estavam vedados a eles até então. Esta oportuna democratização do acesso aos bens simbólicos se articula, no âmbito editorial, como resposta a uma demanda criada pelos projetos de alfabetização em massa implementados no continente desde a década de oitenta do século anterior.

Ampliando e diversificando o panorama cultural da década de vinte, em Buenos Aires, por exemplo, serão criados mais museus de história e ciências naturais; teatros (aos populares em que se encenavam os sainetes das décadas anteriores e ao culto e já existente Colón, se somam o Cervantes e os teatros de variedades); proliferarão os bares e cafés com suas tertúlias (entre as quais figura a famosa "Revista Oral", dirigida por Alberto Hidalgo no Royal Keller, na primavera de 1926); será inaugurado o Conservatório de Música e Artes Cênicas; se fundará a Associação de Amigos da Arte; Le Corbusier oferecerá um ciclo de conferências na Faculdade de Ciências Exatas etc.

No que diz respeito às publicações periódicas, especializadas ou não, circulavam em Buenos Aires, desde fins do século XIX e começos do XX, Caras y Caretas (1898-1939), P.B.T. (1904-1918), Martin Fierro (primeira época, 1904-1905), Nosotros (1907-1934), Fray Mocho, Verbum (do Centro de Estudantes da Faculdade de Filosofia e Letras, 1912-1937); Bambalinas e La Escena (dedicadas ao teatro); folhetins dedicados a autores contemporâneos como La novela semanal, El cuento ilustrado e La novela de bolsillo, cuja distribuição, através das bancas e a preços baixos, os tornava acessíveis a um público mais amplo e diversificado que o leitor tradicional; várias revistas culturais ligadas mais ou menos estreitamente às diversas coletividades de imigrantes (italianos, espanhóis, judeus, alemães, sírio-libaneses, franceses, britânicos, gregos, japoneses etc.), que mediatizavam os difíceis processos de integração e tornavam patente a experiência da fragmentação e heterogeneidade espaçotemporal vivida por cada uma delas ${ }^{16}$. Junto a estas publicações, persistia a presença consolidada no mercado dos suplementos literários dos jornais La Prensa e La Nación (formadores do gosto da classe média e os maiores responsáveis pela profissionalização dos escritores filiados ao Modernismo hispano-americano), ampliada e aprofundada pelas colaborações de autores tão dissímeis quanto Borges e Arlt no mítico Crítica de Natalio Botana, ou as de Arlt no diário ElMundo. Os debates estéticos e políticos da década de vinte acrescentarão a esta longa e não exaustiva lista, revistas como Prisma (primeira revista mural, de 1921), Proa (1922-1923), Inicial (1923-1926), Martín Fierro (1924-1927), Proa (segunda época, 1924-1926), Dínamo, Extrema Izquierda (1924), Los pensadores (1922-1924 e 1924-1926), Claridad (1926-1941) etc.; assim como as diversas "bibliotecas" ou coleções criadas pela Editorial Claridad (Los nuevos, Los poetas, Biblioteca Cientifica etc.), que utilizam o mesmo circuito de distribuição das publicações periódicas de ampla difusão. 
Paradoxalmente, um meio de tão largo alcance como o rádio não se ocupou do debate estético nem se aproximou inicialmente, à exceção da música e do esporte, ao gosto popular; posto que as primeiras emissões de rádio-dramaturgia se produziriam apenas em 1932. Assim, à primeira emissão radiofônica em 27 de agosto de 1920, consagrada à transmissão da ópera Parsifal desde o Teatro Coliseo Argentino, se seguirão emissões regulares em 1921, com programas de música popular e partidas de futebol e, mais tarde, com programas de recitadores. Por sua vez, os escritores se interessaram desde cedo por este meio: Martín Fierro chegou a realizar em 1925, em Rádio Cultura, recitais poéticos em que participou a maioria de seus colaboradores. No entanto, em palavras de Jorge B. Rivera, "la miopía cultural de los grandes pioneros que manejaron el negocio de la radio, junto con las simétricas reticencias elitistas de muchos intelectuales" ${ }^{17}$ contribuíram ao divórcio entre literatura e rádio e ao conseqüente desaproveitamento das potencialidades deste meio, explorado, desde o campo literário, exclusivamente pelos comediógrafos Alberto Vacarezza e Héctor P. Blomberg.

No que diz respeito ao cinema, as primeiras produções foram documentários ou filmes de tema histórico. À projeção dos primeiros filmes ingleses em Buenos Aires em 1896, se seguiu, um ano mais tarde, a primeira filmagem nacional: La bandera argentina de Eugenio Py, quem rodará também, em 1900, a presidente do Brasil à Argentina. Com posterioridade a estas iniciativas pioneiras, se filma o primeiro curta, Escenas callejeras de E. Cardini, realizado com equipamento da casa Lumière, em 1902; enquanto que o primeiro longa-metragem argentino com argumento, que inauguraria uma série de filmes de temática histórica, o realiza Mario Gallo, em 1908, e leva por título La muerte de Dorrego. Embora, inicialmente, vários escritores se interessassem, como espectadores e críticos, no cinema (prova disto são as inúmeras crônicas publicadas por eles em revistas e diários da época, desde as primeiras de Horacio Quiroga às posteriores referências ao cinematógrafo na obra de Raúl e Enrique González Tuñón, Nicolás Olivari, Borges e Arlt, entre outros), as relações entre o cinema e a literatura na Argentina (longe, neste sentido, do Expressionismo alemão) se iniciariam efetivamente apenas na década de 40 com Homero Manzi e Lucas Demare. ${ }^{18}$

Contudo, no período que nos ocupa se produziu uma colaboração singular entre o cinema e a música popular, anterior à série de filmes protagonizada pelo mítico Carlos Gardel a partir de 1930. Com efeito, em 1924, um cinema do bairro portenho de Constitución substituiu o antigo pianista de repertório enciclopédico que acompanhava musicalmente o desenrolar das cenas mudas na tela, por uma "orquestra clássica" com solos de bandônion. Estes solos foram conquistando a platéia ao ponto que o seguinte passo foi a substituição da "clássica" por uma "orquestra típica", cujo repertório estava constituído, integralmente, por tangos. A popularidade alcançada pelo tango junto ao público, aliada à localização da orquestra em um cenário especialmente montado a um lado da tela, deram ao "acompanhamento" musical o caráter de protagonista. Desta maneira, e quando o jazz começou a gozar dos favores do grande público, vários cinemas do centro construíram um palco adicional para a jazz band. E para 1927 - ano em que surgem nos Estados Unidos os dois primeiros longas-metragens falados: O cantor de jazz (discos sincronizados com o projetor) e O sétimo céu (com o som gravado na pista ótica) - esta era a moda em Buenos Aires. ${ }^{19}$ 
Outra associação interessante que se produziu por então, possibilitada pela convivência entre escritores e poetas que exerciam o jornalismo e os canillitas (entre a produção do texto jornalístico e a distribuição do meio impresso), é lembrada por Raúl González Tuñón ${ }^{20}$. Efetivamente, foi "El Diente", chefe de jornaleiros, quem financiou a edição de La crencha engrasada de Carlos de la Púa (pseudônimo de Carlos Raúl Muñoz del Solar, o "Malevo Muñoz" como gostava de se fazer chamar este "malevo vocacional"21). Em agradecimento a este gesto generoso, o volume de "poemas bajos" está dedicado "a todos los canillitas de Buenos Aires y con especial devoción a la figura histórica de El Diente, Don Eduardo Dughera"22. Para além da anedota, a prática jornalística e literária levada a cabo através da imprensa escrita é o signo mais claro da, assim chamada, profissionalização do escritor neste período e desde o período modernista precedente, em sintonia com uma concepção cada vez mais ampla do literário como produção, sobretudo, na visão de Arlt e dos boedistas. Basta mencionar, como exemplo deste livre trânsito entre letras e jornalismo, além das colaborações já referidas de Arlt (na crônica policial) e Borges para Crítica, e de Arlt (com suas águas-fortes portenhas e espanholas) para El Mundo, os trabalhos dos martinfierristas Raúl González Tuñón (“correspondente viajante”), Enrique González Tuñón (atenção do rubro Queixas e Pedidos, e glosas sobre temas de tango), Pablo Rojas Paz (crônicas de futebol), Carlos de la Púa (enviado especial aos Estados Unidos) e Horacio Rega Molina para Crítica $a^{23}$; as freqüentes colaborações de Borges em La Prensa desde julho de $1926^{24}$, e as assíduas dos boedistas nas revistas editadas por Los Pensadores-Claridad.

Exceto no que se refere à preocupação pelo barateio do preço do livro ao consumidor e, em parte, à maior diversificação dos circuitos de circulação do texto literário introduzidas a partir da década de dez na Argentina, este mesmo panorama editorial pode observar-se no México ou no Brasil, países nos quais, aos suplementos literários dos diários e às publicações periódicas especializadas anteriores à década de vinte, vêm se somar, em aberta confrontação com eles, as revistas dirigidas pelos autores alistados nos diversos ismos e centradas no debate estético do momento.

As experiências referidas e outras que descreveremos mais adiante justificam a distinção traçada por Andreas Huyssen entre "vanguarda histórica" e "modernismo" frente à tradição historiográfica anglo-saxã e norte-americana. A respeito, Huyssen sublinha que

[...] a despeito de seu fracasso final, talvez inevitável, a vanguarda histórica queria desenvolver uma relação alternativa entre a alta arte e a cultura de massa, e portanto deve ser diferenciada do modernismo, que em sua maior parte insistiu na hostilidade inerente entre alto e baixo. ${ }^{25}$

Com efeito, a vanguarda histórica latino-americana inicia o processo de inserção do popular nos meios de comunicação de massa, dando lugar, com e por esta prática, às mais heterogêneas e matizadas soluções estéticas a essa matéria. Assim, e embora, a rigor, não se possa falar de um mercado efetivo de circulação de bens simbólicos em uma "cultura de massa" na América Latina senão a partir dos sessenta, a distinção traçada por Huyssen pode nos ajudar a entender a relação conflitante e às vezes contraditória mantida pelos artistas pertencentes aos diversos ismos da vanguarda histórica, ou excluídos deles pelo cânon crítico, com a cultura popular. Poderá nos ajudar a explicar respectivamente produções tão dissímeis quanto as $\mathrm{de} \mathrm{Arlt}^{26} \mathrm{e} \mathrm{Borges}^{27}$, sensíveis, cada um à sua maneira, à 
“dimensão cultural popular"; ou as de Carrera Andrade, Asturias e Oswald de Andrade em relação ao indígena; ou ainda as de Guillén e Carpentier em relação ao afro-caribenho.

Em outro plano, o caráter intrinsecamente fragmentário da constituição dos diversos setores populares, ao qual aludimos acima, produz também, conseqüentemente, diversas modalidades ou tendências em que se cifra o popular entre os bens simbólicos. Neste sentido, é possível distinguir, em diversos pontos da geografia latino-americana, grupos e autores de vanguarda preocupados em diversos graus pelo resgate das tradições indígenas anteriores ou posteriores à conquista - indigenismo, contra o indianismo romântico e o nativismo modernista -; pela valorização da musicalidade, o ritmo e a linguagem afroamericanos - negrismo caribenho -; e pelas falas mestiças e temáticas conseqüentes aos processos de migração - nativismo, coloquialismo urbano, criollismo. Esta última modalidade contava, no Rio da Prata, com o antecedente "culto" da gauchesca, que tinha transformado motivos e uma linguagem artificiosamente gauchescos em tópico literário em poder da elite anterior à imigração européia em massa e que, com esta, se transforma no objeto de uma disputa pela apropriação simbólica capaz de legitimar o direito de pertence de uma identidade nacional, por parte de grupos de diversa extração social.

Ampliado pois nosso campo de análise, vemos reunidas no referido período produções estéticas tais como a narrativa de Roberto Arlt, informada pelos universos discursivos jornalístico (em cujo meio trabalhava), do realismo russo e o rocambolesco de Ponson du Terrail (como leitor das traduções publicadas pela editorial Claridad); a literatura social do grupo de Boedo; a proposta "anarquista" do estridentista Ignacio Millán sobre "la necesidad de dinamitar las ciudades de los versos malditos, para que irrumpiera la plebe de los corridos"28; as passagens que parodiam a fala popular em Macunaíma; a aproximação dos modernistas de São Paulo a formas de espetáculo popular como o circense; a estética kitsch posta em voga pela novela sentimental, de ampla repercussão, e retomada de maneira paródica pelo estridentista Kyn Taniya em Avión, seu livro inicial; a poesia afro-caribenha de Palés Matos e Nicolás Guillén; os diversos meios de resgate da produção indígena e a ampla defesa do exercício dos direitos civis por parte da população indígena, sobretudo no Peru e no México, mas também na Guatemala e no Equador; releituras diversas e até contraditórias da matéria "prima" indígena nacional no Brasil; junto com empreendimentos editoriais tais como as traduções em edições populares - de Editorial Claridad em Buenos Aires - de Dostoievski, Tolstói, Ponson du Terrail, Dickens, Zola; o projeto de divulgação dos clássicos proposto por Vasconcelos através da Secretaria de Educação Pública mexicana em 1921. Todos eles, desde diversos lugares e com objetivos diversos, constituem formas artísticas e/ou institucionais, projetos críticos estéticos e/ou políticos que, de alguma maneira, se preocupam, seja por recuperar o popular no âmbito da produção (dentro de moldes literários que pertencem ou não ao cânon burguês); seja por incluir, no âmbito da recepção da "alta" cultura burguesa, vastos setores populares, rurais ou urbanos; e vice-versa, por projetar a cultura popular em meios até então reservados à "alta" cultura; ou ainda, por questionar os limites entre a cultura "alta" e a "baixa" ou popular, tanto no âmbito da produção quanto no da circulação e recepção.

Com efeito, podemos ver que alguns destes gestos e iniciativas individuais, grupais ou institucionais poderiam interpretar-se como questionamento e ataque do que Bürger chama a "arte como instituição". 
Contudo, embora possa se dizer que, em geral, a valorização do popular teve, para alguns grupos que surgiram neste período, um caráter de questionamento do academicismo, não todos os grupos utilizaram esse recurso com esta função. Alguns inclusive, como os boedistas através da Editorial Claridad, acabaram estabelecendo um novo cânon no qual o popular acedeu a um espaço literário, se não estritamente acadêmico, pelo menos com um certo grau de legitimação. Neste caso, mais do que de um questionamento direto do academicismo, trata-se, em palavras de John Beverley, "de encontrar maneras de transferir la negatividad constitutiva de lo subalterno a los estamentos de la cultura dominante". ${ }^{29}$

Neste sentido, é importante destacar que para litigar esta legitimação, os setores subalternos levaram à prática operações cuja instrumentalização tinha sido possível até então exclusivamente para a cultura burguesa hegemônica; operações essas mediatizadas por publicações de diversos tipos, como os suplementos literários, as revistas especializadas e, em geral, a organização dos saberes em diversas coleções bibliográficas. Assim sendo, e impossibilitados de tomar por assalto os espaços vedados ao popular (como o eram, por exemplo, os suplementos literários dos periódicos tradicionais, frente aos quais também Martín Fierro adotará um distanciamento performático), os setores subalternos criaram seus próprios meios e circuitos de circulação como antes o tinham feito os anarquistas através da imprensa periódica, o folhetim e o teatro. A legitimação da cultura dos setores subalternos esteve, pois, ligada estreitamente à aquisição (também fragmentada, isto é, a prestações) e aproveitamento dos meios de reprodução técnica ${ }^{30}$, que facilitaram no período a (con)fusão perturbadora e a difusão de diversos discursos, às vezes em um mesmo suporte.

Por outro lado, a utilização destes meios proporcionou também à Editorial Claridad uma sorte de compasso que harmonizou positivamente, em termos financeiros, a produção e consumo dos bens simbólicos por ela introduzidos no mercado; no sentido de que, o uso dos novos meios técnicos de reprodução diminuiu o necessário "délai de réponse entre l'investissement culturel et la réponse économique", característico do mercado intelectual desde fins do século XIX de acordo com Leenhardt ${ }^{31}$.

Neste sentido também, ao falar de arte moderna e produção industrial, Adorno se referirá à potencialização da produção estética pelos meios de (re)produção industrial nestes termos:

Cualquier obra, al ser una unidad destinada a muchos, es ya en su misma idea una reproducción de sí misma. ${ }^{32}$

Em meio a considerações que, com as ressalvas necessárias, poderíamos aplicar ao contexto latino-americano, muito heterogêneo no que diz respeito à implantação dos meios de produção industrial, o teórico alemão definirá:

Es arte moderno el que por su forma de experimentar, y como expresión de la crisis de la experiencia, absorve todo aquello que la industrialización en las formas dominantes de producción ha conseguido llevar a sazón. ${ }^{33}$ 
Com efeito, é possível interpretar dialeticamente o empreendimento editorial levado a cabo pelos intelectuais de Los Pensadores-Claridad como uma manifestação do negativismo crítico atribuído por Adorno à arte moderna, pela utilização dos meios de produção industrial como instrumento para questionar os modos de produção e os circuitos canônicos instituídos pela arte acadêmica, embora não propriamente (e mais radicalmente) como forma de experimentação estética.

Um outro elemento em que se pode verificar a heterogeneidade e fragmentação regionais, como dizíamos acima, é a divergência quanto à seleção de aspectos culturais em que se cifrou a valorização do popular e, sobretudo, à significação dada aos mesmos. Assim, em alguns casos, a valorização do popular aparece associada a um certo primitivismo: deste cunho é a defesa que Maples Arce fará da obra do "bárbaro" Diego Rivera ante os primeiros ataques das "porras académicas" 34 . Em outros, o popular aparece associado ao passado rural visto nostalgicamente desde um presente urbano, e assume o valor de significante do nacional que se opõe ao significante atribuído por outros grupos contemporâneos. Assim, na polêmica que enfrentou os grupos de Florida e Boedo em torno a "lo nuestro", o popular aparece representado nas obras dos de Boedo pelo cotidiano urbano contemporâneo, enquanto que entre os de Florida a figuração de "lo nuestro" adota uma visão nacionalista e mitificadora, quando não novidadeira, do criollo e o espaço suburbano. Em outros ainda, o popular aparece associado a expressões do autóctone e assume, além disso, uma função política, como é o caso do indigenismo peruano. E, em geral, o popular aparece associado em todo o continente, como dizíamos acima, a diversas expressões de grupos sociais subalternos ou, em outras palavras, dando nova vazão ao que Antonio Cornejo Polar denomina "literaturas heterogéneas" 35.

Dentre elas caberia incluir pois, por um lado, as valorizações do popular exercidas sobre materiais provenientes de diversas culturas marginais em relação à cultura "alta" e hegemônica; e paralelamente, por outro, as defesas dos setores sociais que as representam. Com efeito, as tendências valorizadoras do indigenismo, do negrismo e ainda de um certo criollismo afirmam formulações e figurações diversas de algo que, frente à "alta" cultura representada pelos modelos estéticos europeus do período anterior, poderia entender-se como expressão, com modulações variadas, de uma sorte de primitivismo ou autoctonismo americanos.

Por outra parte, essas afirmações expressam também a oposição de alguns desses grupos e autores à aplicação de um modelo de modernização importado, cuja implementação implica o sacrifício dos setores sociais subalternos defendidos por eles. Nesta linha, poderíamos citar como exemplo os poemas indigenistas do equatoriano Jorge Carrera Andrade. Em uma outra linha, que combina a defesa do setor indígena subalterno mas aprova a modernização, inclusive como meio de reivindicação desse setor, encontramos os ensaios e o trabalho jornalístico de José Carlos Mariátegui. Em outra ainda, Miguel Ángel Asturias levará a cabo em sua narrativa uma crítica do modelo de modernização além de uma, paralela e mais importante, recuperação de mitos e lendas maias através da elaboração poética desse mundo mágico por um prisma surrealista.

Assim também serão diferentes entre si as formulações da poesía negra de Nicolás Guillén, Emilio Ballagas e Luis Palés Matos, ao promover valorizações de aspectos diver- 
sos (poéticos, musicais, plásticos, políticos) da cultura afro-caribenha. E, em geral no período, o surgimento e coexistência de uma diversidade sem precedentes de séries e formas narrativas ${ }^{36}$.

Neste vasto e diversificado material que vimos citando, caberia fazer ainda outras distinções. Se levamos em consideração, em geral, o momento histórico de surgimento das produções de corte popular que interessaram a diversos autores ou grupos de vanguarda, podemos distinguir: as contemporâneas às produções de vanguarda e as pertencentes ao passado histórico cultural e literário. Entre estas últimas cabe distinguir ainda: as provenientes da tradição indígena e da própria cultura popular americana (já mestiça, crioula); e as provenientes das literaturas européias.

No caso das produções contemporâneas às da vanguarda se encontrariam as de alguns boedistas, como Castelnuovo e Mariani, ambientadas no espaço urbano e focalizadas em personagens representativos de camadas sociais comuns, em algumas de suas obras, aos da novela semanal.

No caso das produções pertencentes ao passado histórico cultural e literário, as referências se multiplicam. Por um lado, estariam as que tomam como referente às culturas indígenas americanas, em suas manifestações anteriores e posteriores à conquista. Nesta linha podemos citar boa parte da produção narrativa de Asturias - posterior à sua colaboração na tradução para o castelhano do Popol-Vuh (1923-1927) -; e o estereótipo indígena introduzido por Rivera, Charlot e outros a partir dos murais da Secretaria de Educação Pública (1923-1928): a primeira destas produções está inspirada na tradição maia; enquanto que a pictórica toma como matéria de incitação estética tanto a tradição maia como outras tradições indígenas mexicanas.

Por outro lado, encontramos produções cujo marco de referência se situa em produções européias desprestigiadas ou sem maior valor no momento para a própria vanguarda européia. Seria o caso da narrativa arltiana, intrinsecamente relacionada com a tradição realista russa - Dostoievski - e o popular folhetim francês - Ponson du Terrail.

Já no que se refere ao tratamento estético dado ao popular contemporâneo como matéria poética, podemos distinguir duas soluções preponderantes: uma que associa esta matéria ao cotidiano e a inscreve em um registro realista; outra que a submete a uma nova forma, sintética e fragmentária, mais numerosa em seu momento e que seria precursora da narrativa das décadas de sessenta e setenta. Exemplos de escritura em registro realista são as produções dos escritores de Boedo e parcialmente as de Arlt. Exemplos de uma escritura sintética e fragmentária são as produções do estridentismo mexicano - Esquina (1923), de List Arzubide; La Señorita Etcétera (1922), de Arqueles Vela, publicada na coleção "La Novela Semanal" de El Universal Ilustrado? e algumas do martinfierrismo rio-platense - a anotação do viajante nos Veinte poemas para ser leídos en el tranvía (1922), de Girondo, e aquela que traça o observador que, perambulando pela cidade, descobre seu Fervor de Buenos Aires (1923).

Outra distinção ainda diz respeito às implicações teóricas que coloca, enquanto à sua função estética, a valorização do popular neste período. Se bem sabemos que o questionamento da distinção entre "alta" e "baixa" cultura, postulado pelos grupos de vanguarda, foi tratado programaticamente e com beligerância nos manifestos, a produção literária extra-manifestos mantém uma relação ambígua com ele, sobretudo no que tange 
ao componente lingüístico. Independentemente da tendência preponderante em cada zona cultural, é possível perceber a presença desta ambigüidade em diversas produções da vanguarda latino-americana. Apenas para citarmos aqui dois exemplos emblemáticos, a poética inicial de Borges foi parcialmente caudatária da tradição criollista de corte populista. No entanto, nas sucessivas edições de seus três primeiros livros de poemas, ele foi substituindo a linguagem criollista por vocábulos "castiços", mesmo quando o ambiente evocado fosse ainda o do arrabalde portenho. Por sua vez, Mário de Andrade se apropria parodicamente da fala popular em Macunaíma, outorgando-lhe à estratégia ("brincadeira" e "pesquisa") uma função claramente anti-academicista. Seu jogo se orienta deliberadamente à afirmação renovada da identidade nacional perante uma arte acadêmica que nega ou oculta as manifestações do popular.

No que diz respeito ao plano lingüístico-discursivo, uma característica generalizada no período é a da produção de discursos mais próximos dos atos de fala. Programaticamente, esta estratégia aparecerá nos manifestos: da Poesia Pau-Brasil, do jornal Leite criôlo, na apresentação de Terra Roxa e outras terras, em El movimiento estridentista de Germán List Arzubide. O coloquialismo ou o prosaísmo estarão presentes também na poesia de N. Olivari e de R. González Tuñón e na narrativa dos boedistas e de Arlt.

Mesmo que tomadas estas formas como expressões do questionamento da arte como instituição, emparentadas, mais ou menos explicitamente, com propostas de corte primitivista, caberia ainda distinguir o primitivismo latino-americano do europeu contemporâneo. O primitivismo latino-americano representa uma vontade consciente de retorno à origem, ao primigênio, ao autóctone, ao grau zero da cultura do continente. Origem como cifra e possibilidade de execução de algo radicalmente novo, contra os modelos gastos na produção e o automatismo na recepção. No entanto, não há, como apontáramos acima, uma distinção histórica clara entre a época de produção dos materiais que se tomam como objeto de incitação estética ou de modo menos mediatizado como temática. Em outras palavras, na medida em que, em países cuja população a indígena ou a de origem africana constituem quantitativamente a base maior (embora funcionando socialmente como maiorias excluídas do poder), se vislumbram na arte popular elementos nos quais se perpetua ("vive", dirá Siqueiros) uma arte mais propriamente "primitiva" (a indígena pré-colombiana ou a africana) e se dá a ambas - popular e primitiva - um tratamento similar. E isto vale também para o tratamento dado, em diversos âmbitos das artes no período, à arte popular propriamente dita, aquela produzida durante a Colônia ou o período republicano.

Em contraste com esta característica do primitivismo latino-americano, o primitivismo europeu passou por distintas etapas ${ }^{37} \mathrm{em}$ seu interesse e apropriação do primitivo: primeiro, a "descoberta" e contato direto com a escultura primitiva na Alemanha e na França; posteriormente, a incorporação da arte infantil e da arte popular e, mais tarde, a da arte inconsciente, que acabarão substituindo o referencial aborígene. No entanto, no prospecto de assinatura de Der Blaue Reiter Almanac, em maio de 1912, já Franz Marc escrevia:

Da consciência dessa secreta conexão de todas as novas produções artísticas, desenvolvemos a idéia do Blane Reiter. [...] O primeiro volume anunciado por meio deste [...] inclui os 
últimos movimentos na pintura francesa, alemã e russa. Revela as conexões sutis com a arte gótica e primitiva, com a África e o vasto Oriente, com a arte altamente expressiva do popular espontâneo e da criança, e particularmente com os mais recentes movimentos musicais da Europa e as novas idéias do teatro do nosso tempo. ${ }^{38}$

No âmbito latino-americano poderia se dizer que cada artista ou grupo (re)descobre as formas primitivas e populares de sua respectiva zona cultural. Com efeito, embora as tendências que apontamos aqui não se restrinjam rigorosamente a uma zona cultural determinada, a cultura da zona respectiva funciona, de alguma maneira, como condição de produção predominante e explica certas constantes. Neste sentido, é possível estabelecer, contrastivamente, analogias quanto à coincidência, com diversos graus de relevância, de uma mesma tendência em diversas zonas culturais. Assim, se o indigenismo constitui a tendência predominante em mais de uma zona (México e Peru), o coloquialismo e o prosaísmo predominam no Rio da Prata, mas também estão presentes, com diverso grau de importância e realizações bem diversas, nas propostas estéticas e na poesia mexicanas, cubanas e peruanas, e na prosa brasileira do período.

Por outro lado, embora coincidentes quanto à tendência predominante, diversas zonas atribuem à essas tendências funções simbólicas e políticas diferentes. Em oposição aos próprios realizadores, o indigenismo do muralismo mexicano foi pensado, a partir do âmbito do poder político, como instrumento da propaganda estatal para incentivar a participação dos setores indígenas analfabetos na campanha de alfabetização (que deixava de lado deliberadamente as línguas indígenas) promovida pelo Estado. Já o indigenismo peruano se constitui no pensamento de Mariátegui —embora o pensador peruano tenha por objetivo último a implantação do socialismo — no instrumento de promoção e participação dos setores indígenas subalternos no modelo de modernização imposto no momento pela oligarquia econômica aliada ao poder do Estado.

Da mesma maneira, embora mais profundamente, a matriz cultural regional - a indígena - é análoga no muralismo mexicano, no pensamento de Mariátegui, no Peru, e na Antropofagia de Oswald de Andrade, mas as propostas estéticas, culturais e sociais que veiculam, bem como as realizações de cada uma destas tendências, são de ordem diversa.

\section{Notas}

\footnotetext{
${ }^{1}$ Ambas noções estão intrínsecamente condicionadas pela variável histórica. Assim, a primeira definição que R. Williams dá acerca da "civilização" é que "is now generally used to describe an achieved state or condition of organized social life”, enfatizando seu caráter de resultado de um processo. Já em relação à noção de "cultura", o historiador inglês distingue: "(i) the independent and abstract noun which describes a general process of intellectual, spiritual and aesthetic development, from C18; (ii) the independent noun, whether used generally or specifically, which indicates a particular way of life, whether of a people, a period, a group, or humanity in general, from Herder and Klemm. [...] (iii) the independent and abstract noun which describes the works and practices of intellectual and especially artistic activity. [...] The complex of senses indicates a complex argument about the relations between general human development and a particular way of life, and between both and the works and practices of art and intelligence." Cf. Williams, R. Keywords: a vocabulary of culture and society. New York, Oxford UP, ca.1983, pp.57-60 e 87-93. As citações correspondem
} 
às pp.57, 90 e 91, respectivamente (grifos nossos). Para uma breve história contrastiva destas noções, $c$. Williams, R. Culture \& Society, Coleridge to Orwell. London, The Hogarth Press, 1992, pp.254 et passim.

2 Andrade, O. de, Manifesto antropófago, in: A utopia antropofágica. São Paulo, Globo, 1990, p.51.

${ }^{3} C f$. Leenhardt, J., "Maturation historique des conditions d'apparition des avant-gardes", in: Weisgerber, J. (dir.). Les avant-gardes littéraires an XXe. siècle. Bruxelles, Centre d'étude des avant-gardes de l'Univ. de Bruxelles, s.d., pp.1059-1072. A citação corresponde à p.1064.

${ }^{4}$ A partir da noção de intertextualidade, M. Lienhard desenvolve este conflito como característico da literatura latino-americana e o exemplifica na literatura contemporânea. Cf. Lienhard, M. "Moriencia: una intertextualidad indoamericana”, in: Texto crítico. Veracruz, Univ. Veracruzana, a.VIII, nº24-25, jan.-dez. de 1982, pp.142-160.

${ }^{5}$ Halperin Donghi refere-se a um "avance por explosiones", em sua Historia contemporánea de América latina. Madrid, Alianza, 1998, p.280. A respeito deste processo são de particular importância os capítulos 4 e 5 desta obra, "Surgimiento..." e "Madurez del orden neolonial".

${ }^{6}$ Cf. Focillon, H., "Arte e Cultura Populares", in: Revista Brasileira de História. São Paulo, vol. 8, nº15, set. de 1987-fev. de 1988, pp.205-214. As citações correspondem às pp.210-213.

${ }^{7}$ Cit. por M. Chaú em O nacional e o popular na cultura brasileira. Seminários. São Paulo, Brasiliense, 1984, p.1617.

${ }^{8}$ Cabe destacar suas obras Cânticos sertanejos, Choros, Serestas e Cirandas.

${ }^{9}$ Ver a respeito o artigo de Aaron Copland, "Carlos Chávez, compositor", em CONTEMPORÁNEOS, a.1, vol.2, nº7, dez. de 1928, pp.407-412. Na opinião de Copland, Chávez é "absolutamente contemporáneo [...] porque usa sus dotes de compositor en la expresión de la belleza objetiva de significación universal..." Segundo Sheridan, este elogio é do mesmo tipo que o expressado por García Maroto em relação a Rivera (CONTEMPOR ÁNEOS, a.1, vol.1, nº jun. de 1928, pp.43-75) e que, "en las circunstancias nacionalistas, se convertía en insulto". Cf. Sheridan, G. Índices de CONTEMPORÁNEOS. México, UNAM, 1988, p.42. Sobre a polêmica nacionalista que haveria de incendiar o meio intelectual mexicano em 1932 e que enfrentaria, do lado da modernidade e da internacionalização da arte mexicana, os "Contemporáneos" e seu mentor Alfonso Reyes e, do lado nacionalista, Ermilo Abreu Gómez e Héctor Pérez Martínez entre outros, ver do próprio Sheridan, México en 1932: la polémica nacionalista. México, FCE, 1999.

Com relação ao problema que nos ocupa, cabe destacar as composições El fuego nuevo (1928) e Sinfonía india (1935) de Chávez; e Cuaubnábuac (1931), Janitzio (revista em 1936) e La noche de los mayas de Revueltas. Deste último também vale lembrar composições que dialogam com as artes plásticas, como seus "murais de som" Caminos (1934) e Itinerarios (1938), e com a literatura, como Sensemayá (1938), inspirado no poema afrocaribenho de N. Guillén. Sobre Revueltas, $c f$. Kolb Neuhaus, R. "Silvestre Revueltas: Tale of an Unforgivable Oblivion", in: www.peermusic.com/classical/Revueltasessay.htm

${ }^{10}$ A respeito, cabe citar suas obras Impresiones del altiplano (1935), o bailado Panambi (1940), baseado em uma lenda guarani; e Estancia, sobre cenas da vida rural argentina.

${ }^{11} \mathrm{~J}$. E. Pacheco se ocupa da continuidade desta linha na poesia mexicana e de seus contatos com a "New Poetry" norte-americana em "Nota sobre la otra vanguardia", in: Revista Iberoamericana. Pittsburgh, vol. XLV, n'106-107, jan.-jun. de 1979, pp.327-334.

${ }^{12}$ García Canclini, N. "La crisis teórica en la investigación sobre cultura popular", in: Homines. Hato Rey (Puerto Rico), vol. 12, n¹-2, mar. de 1988-jan. de 1989, pp.38-55. As citações correspondem às pp.50 e 45, respectivamente. Em coincidência com García Canclini, J. Beverley dirá "el concepto de lo subalterno no designa una identidad pre- o para-capitalista, sino precisamente una relación de integración diferencial y subordinada dentro del tiempo del capital." Cf. "Subalternidad / modernidad / multiculturalismo", in: Revista de crítica literaria latinoamericana. Lima-Hanover, año XXVII, nº53, $1^{*}$. sem. de 2001, pp.153-163; a citação corresponde à p.154.

${ }^{13}$ A. Gorelik aponta a este respeito que "en América, la modernidad fue un camino para llegar a la modernización, no su consecuencia". Cf. "Lo moderno en debate: ciudad, modernidad, modernización", in: www.bazaramericano.com/bazar/articulos/moderno_gorelik.ASP

${ }^{14}$ Williams, R. "Introduction", in: Culture \& Society, op. cit., pp.XIII-XX; a citação corresponde à p.XVI.

${ }^{15}$ Sarlo, B. "Lo popular en la historia de la cultura", in: Punto de vista. Buenos Aires, a.XII, nº35, set.-nov. de 1989, pp.19-24; as citações correspondem à p.24. 
${ }^{16}$ Cf. a respeito, Pujol, S. A. "Las revistas culturales de los inmigrantes en Buenos Aires (1914-1930)", in: Todo es Historia. Buenos Aires, n²12, 1984, pp.46-55.

${ }^{17}$ Rivera, J. B. "La forja del escritor profesional (1900-1930). Los escritores y los nuevos medios masivos (II)", in: Historia de la literatura argentina. Buenos Aires, CEAL, 1980/1986, vol.3, p.382.

${ }^{18}$ Sobre este particular, são de grande utilidade os dois capítulos escritos por Jorge B. Rivera, "La forja del escritor profesional (1900-1930). Los escritores y los medios masivos (I y II)”, op. cit., vol. 3, pp.337-360 e 361-384, assim como as cronologias constantes nos volumes 2, 3 e 4 da Historia citada.

${ }^{19} \mathrm{Cf}$. a respeito a história do tango escrita por Francisco García Jiménez, rica em anedotas, El tango. Historia de medio siglo: 1880/1930. Buenos Aires, Eudeba, 1964; em especial, pp.70-73.

${ }^{20}$ Em entrevista realizada por Juan Cedrón (ca. 1970), in: Cuarteto Cedrón. Todo Raúl González. Tuñón. Paris, Gotán, 1994, faixa 5 do disco compacto.

${ }^{21}$ Assim o lembra C. Nalé Roxlo em seu Borrador de memorias. Buenos Aires, Plus Ultra, 1978, p.22.

${ }^{22}$ A segunda parte do livro, "Los Laburos", está dedicada "a mis rivales en el cariño a Buenos Aires: Nicolás Olivari, Raúl González Tuñón y Jorge Luis Borges”. Cf. de la Púa, C., La crencha engrasada. 2.e. Buenos Aires, Ed. Porteña, 1954, p.77.

${ }^{23}$ Cf. Rivera, Jorge B., op. cit., pp.371-373.

${ }^{24}$ Cf., a respeito, Borges, J. L. Textos recobrados, 1919•1929. Buenos Aires, Emecé, 1997.

${ }^{25}$ Cf. Huyssen, A. "Introdução", in: Memórias do modernismo. Rio de Janeiro, Ed. UFRJ, 1997, pp.8-9. A distinção proposta por Huyssen está inspirada na Teoría de la vanguardia de P. Bürger, quem caracteriza o modernismo como uma crítica esteticista do sistema de valores burguês inseparável, em última instância, da arte enquanto instituição burguesa; e a vanguarda como uma autocrítica e ataque à instituição arte, tendente a reintegrar a arte em uma nova práxis vital, e como origem de um tipo de arte inorgânica. Contudo, a preocupação pela constituição de um paradigma teórico baseado precisamente em "la superación de la divergencia entre la institución y el contenido" das obras concretas (p.65), levará Bürger a descuidar do tratamento de relações intermediárias entre "alta" e "baixa" cultura experimentadas pelos movimentos da vanguarda histórica. A respeito, cf. P. Bürger, Teoría de la vanguardia. Barcelona, Península, 1987.

${ }^{26}$ Desconfiados da existência da diferença apontada mais tarde por Huyssen, os editores de Claridad (que obtusamente tinham se recusado a publicar o romance por sugestão de Castelnuovo) expressarão na nota bibliográfica dedicada ao lançamento de Eljuguete rabioso: "Se trata de la vida de los muchachos del suburbio, de sus pillerías y aventuras. El título es un tanto caprichoso y modernista y no condice con el espíritu del libro". Cf. Claridad, a.1, n5, nov. de 1926. Como sabemos, o título que Arlt tinha dado inicialmente a seu romance era La vida puerca, mais apropriado a seu "espíritu"; com efeito, El juguete rabioso foi sugerido pelo "modernista" Güiraldes. Sobre a recusa do manuscrito por parte de Castelnuovo para a coleção Los nuevos, cf. Arlt, M. e Borré, O. Para leer a Roberto Arlt. Buenos Aires, Torres Agüero, 1984, p.51.

${ }^{27}$ Arlt e Borges foram apresentados pela crítica especializada, durante muito tempo, como emblemas contrastantes da escritura do período. No entanto, e apesar das diferenças de formação e produção estéticas que os separavam, já em 1929, após ganhar o segundo prêmio municipal de prosa com El idioma de los argentinos, Borges reconhecia os méritos de Arlt. À pergunta "A quién lee de los nuevos" da revista bibliográfica La Literatura Argentina, responde: “[...] Y de prosa es notable Roberto Arlt. También Eduardo Mallea. No veo otros". Cf. Borges, J. L. Textos recobrados, op. cit., p.398.

${ }^{28}$ Cit. por G. List Arzubide em "El movimiento estridentista”, in: Schneider, L. M. El Estridentismo. México, 1921-1927. México, UNAM, 1985, p.293. Reproduz a edição original de Jalapa, Ediciones de HORIZONTE, 1926.

${ }^{29}$ Beverley, J., op. cit., p.156.

${ }^{30}$ Por outra parte, em palavras de Huyssen, "a tecnologia tem um papel crucial, se não o papel crucial, na tentativa da vanguarda de superar a dicotomia arte/vida e tornar a arte produtiva para a transformação do cotidiano". Cf. "A dialética oculta: vanguarda-tecnologia-cultura de massa", op. cit., p.29.

${ }^{31}$ Cf. Leenhardt, J., op. cit., p.1065.

${ }^{32}$ Adorno, Th., Teoría estética. Barcelona, Orbis, 1983, p.52.

${ }^{33}$ Id., ibid., p.53.

${ }^{34}$ Cit. por List Arzubide, G., em "El movimiento estridentista", op. cit., p.282. 
${ }^{35}$ Cornejo Polar, A., "El indigenismo y las literaturas heterogéneas: su doble estatuto socio-cultural", in: Revista de crítica literaria latinoamericana. Lima, a.IV, no7-8, 1*.-2*. sem. de 1978, pp.7-21.

${ }^{36} \mathrm{Na}$ narrativa, é interessante destacar a diversidade de caminhos abertos ou retomados. Com efeito, coincidem temporalmente novelas de la tierra como La vorágine (1924) ou Doña Bárbara (1929), com Don Segundo Sombra (1926) ou El águila y la serpiente (1928), por um lado; com a novela lírica dos "Contemporáneos", por outro; e ainda estas, com o romance social dos boedistas ou Eljuguete rabioso (1926). Para o estudo da relação conflitante entre vanguardismo e regionalismo em particular, of. Rama, A. Transculturación narrativa en América Latina. 2.e. México, Siglo XXI, 1985, pp.20-32. Para o estudo da narrativa de vanguarda, cf. Achugar, H., "El museo de la vanguardia: para una antología de la narrativa vanguardista hispanoamericana", e Verani, H., "La narrativa hispanoamericana de vanguardia", in: Verani, H. (ed.). Narrativa vanguardista hispanoamericana. México, UNAM-Ediciones del Equilibrista, 1996, pp.7-40 e 41-73, respectivamente.

${ }^{37}$ Cf. Goldwater, R. Le primitivisme dans l'art moderne. Paris, PUF, 1988, pp.234-235.

${ }^{38}$ Cit. por M. Perloff, O momento futurista: avant-garde, avant-guerre, e a linguagem da ruptura. São Paulo, Edusp, 1993, p.171 (grifo nosso). 